Insight, part of a Special Feature on The Privilege to Fish

\title{
Salmon, Science, and Reciprocity on the Northwest Coast
}

\author{
D. Bruce Johnsen $^{1}$
}

\begin{abstract}
Severe depletion of many genetically distinct Pacific salmon populations has spawned a contentious debate over causation and the efficacy of proposed solutions. No doubt the precipitating factor was overharvesting of the commons beginning along the Northwest Coast around 1860. Yet, for millenia before that, a relatively dense population of Indian tribes managed salmon stocks that have since been characterized as "superabundant." This study investigates how they avoided a tragedy of the commons, where in recent history, commercial ocean fishers guided by scientifically informed regulators, have repeatedly failed. Unlike commercial fishers, the tribes enjoyed exclusive rights to terminal fisheries enforced through rigorous reciprocity relations. The available evidence is compelling that they actively husbanded their salmon stocks for sustained abundance.
\end{abstract}

Key Words: exclusive tribal rights; information feedback; potlatching; reciprocity; resilience; salmon husbandry

\section{INTRODUCTION}

Severe depletion of many genetically distinct Pacific salmon (Oncorhynchus sp.) populations has spawned a contentious debate over causation and the efficacy of various solutions (Kareiva et al. 2000, Dumbacher et al. 2001). Although hydropower, habitat degradation, and ill-informed hatchery management have surely contributed to the decline (Mann and Plummer 2000), the precipitating factor was undoubtedly the race to harvest salmon with the advent of marine fishing following cannery operations all along the Northwest Coast (NWC) between 1860-1880 (Harris 2001). The Pacific salmon fishery has since become the prototype of an open-access, commonpool resource. Despite ever-tightening regulation, it is now a "tragedy of the commons" unfolding in real time.

In his 1968 article by that name, ecologist Garrett Hardin outlined the conditions that would lead rational people to overuse and even destroy an openaccess commons (Hardin 1968). He identified two possible solutions: government regulation and government-established private-property rights. Although seminal, Hardin's insights are now seen as simplistic. A mounting body of social science research shows that "for thousands of years people have self-organized to manage common-pool resources, and users often do devise long-term, sustainable institutions for governing these resources" (Ostrom et al. 1999). No single institutional arrangement suits all settings (Dietz et al. 2003), but local self-governing institutions relying on some form of reciprocity often dominate top-down regulation (Ostrom et al. 1999).

To halt the tragedy now unfolding in the Pacific salmon fishery, it is essential to learn from evolved institutional arrangements in other settings. A remarkable example is close at hand. Before the arrival of the canneries, the fishery was prolific, with salmon runs said to be superabundant based on early European accounts (Langdon 1979). For millennia before that, the various tribes inhabiting the NWC relied on this abundance to support a relatively dense sedentary population and a high standard of living. Lacking the ability to catch large numbers of salmon in the open sea, the tribes harvested them primarily in terminal, river-based fisheries subject to exclusive tribal property rights (ETRs) enforced through long-term reciprocity relations.

The traditional view of the NWC tribes has been that they were subsistence hunter-gatherers who 
had the good fortune to inhabit a region naturally abundant with resources, especially Pacific salmon. Although this view may have originated with early anthropologists (Boas 1966, Donald 1997), it was quickly adopted by Canadian fisheries regulators as an expedient for restricting native access to the salmon fishery (Harris 2008). Substantial anthropological work has since been done pointing out the relationship between tribal culture, institutions, and productivity (Langdon 1979, Menzies and Butler 2007), but the traditional characterization of the tribes as subsistence huntergatherers inhabiting a land of natural abundance seems to have stuck in the mind of the general public.

This article provides an alternative to the traditional view. When seen through the lens of property-rights economics (Coase 1960), the weight of the evidence suggests the NWC tribes built salmon abundance over millennia of purposeful salmon husbandry. Far from being subsistence hunter-gatherers, they are better characterized as salmon ranchers.

The tribes' institutions are the key to understanding their success and possibly to resolving the current looming tragedy. Influenced by the peculiar biology of Pacific salmon, these institutions effectively functioned to resolve conflict, promote technological development, provide reliable information, provide feedback about the environmental effects of resource-harvesting decisions, and encourage the accumulation and transfer of relevant knowledge (Dietz et al. 2003).

\section{THE BIOLOGY OF PACIFIC SALMON}

Although their life histories differ, the five species of Pacific salmon-chinook (Oncorhynchus tschawytscha), chum (Oncorhynchus keta), coho (Oncorhynchus kisutch), pink (Oncorhynchus gorbuscha), and sockeye (Oncorhynchus nerka)share three important biological characteristics. Most obviously, they are anadromous. Born in freshwater lakes or streams, they eventually make their way to sea, where they spend most of their adult lives. In anywhere from 1-5 years, depending on the species, they return to their natal stream as a cohort to spawn. The cohort, known as a "run," is one among an unending series of cohorts that make up the "stock" of successive generations. A given river system may support multiple species and multiple stocks within a species.
Pacific salmon are also semelparous. They are born in large numbers, reproduce only once before dying, grow quickly, suffer high mortality, live fairly short lives, and are extremely fecund. They are a classic example of an r-selected species (Hayden 1981). Cohort competition throughout their life cycle is intense.

Finally, Pacific salmon are extremely heritable. The time between generations is short enough, and the struggle to reproduce is keen enough, that over the course of a man's lifetime the biological characteristics of a given salmon stock can evolve dramatically in response to even minor changes in environment. One study shows that reproductive isolation of the members of a common population can lead to ecological speciation in as little as 55 years (Hendry et al. 2000). Furthermore, many of the unique physical characteristics of different populations are easily observed. As one naturalist, reported in 1874, "[e]very river, every brook, every lake stamps a special character upon its salmon... which is at once recognized by those who deal in or consume them" (Marsh 1874).

\section{THE NWC TRIBES AND THEIR INSTITUTIONS}

For over 10000 years, the NWC tribes inhabited the many islands and inland waterways of the Pacific coast of North America (Fig. 1). Running from northern California to the Alaska panhandle, the region contains countless rivers and streams, many of which descend from rugged coastal mountains to the sea. Several of these, most notably the Columbia, the Fraser, the Skeena, and the Nass, originate hundreds of miles inland, fed by various upstream tributaries. At the time of European contact, virtually all rivers and even many smaller streams in the region supported one or more species of Pacific salmon.

For thousands of years before European contact, the NWC tribes were sedentary, having an acute attachment to place and claiming exclusive ownership of smaller river systems and the territories they drained. Conditional on their strong attachment to place and their inability to harvest large numbers of salmon in the open sea, they effectively owned the salmon stocks that spawned in their streams and harvested them largely in terminal fisheries during their upstream migration. Although they were diverse in linguistic origins, the 
Fig. 1. The Northwest Coast. Reprinted with permission from University of California Press.

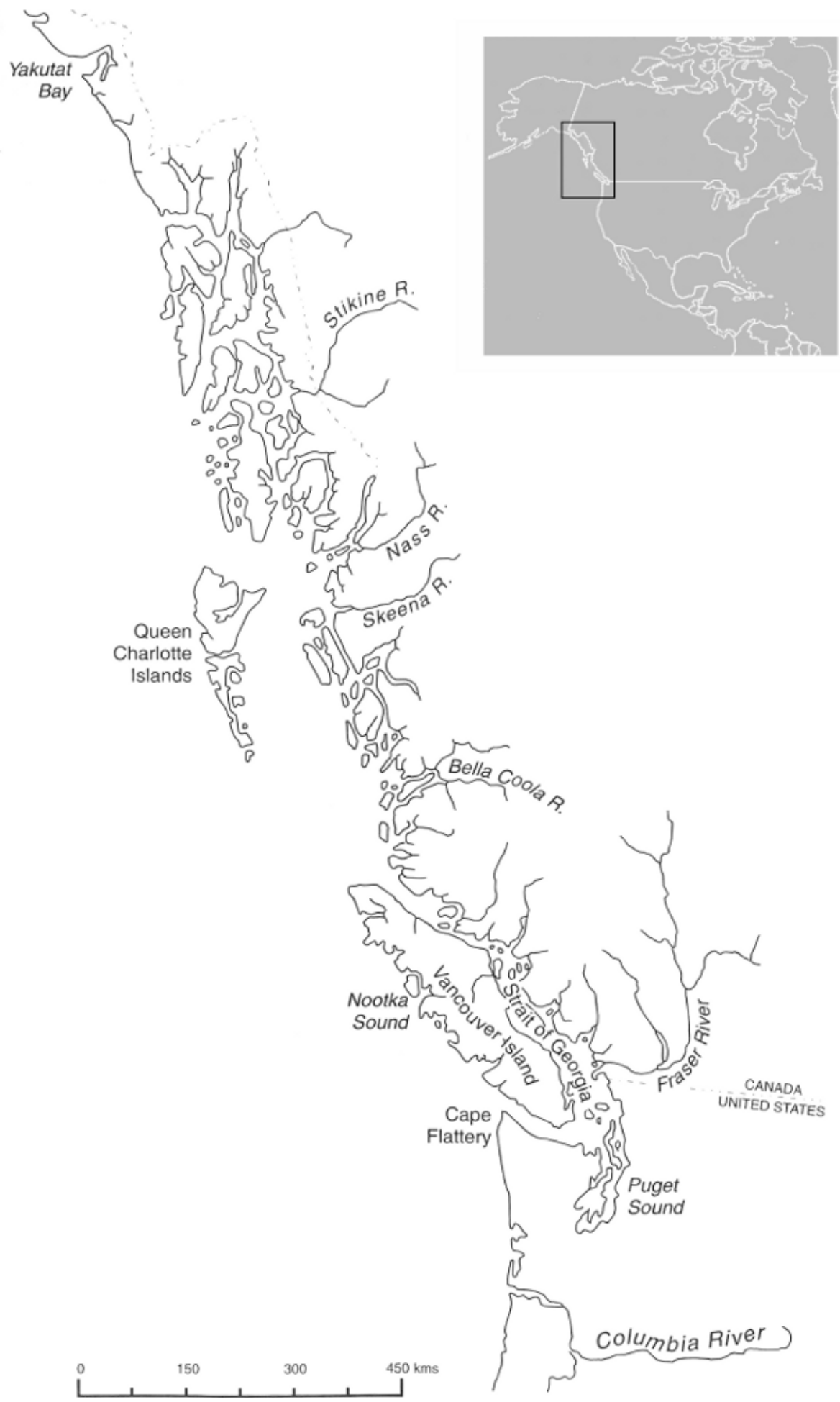


tribes had in common a heavy reliance on salmon as their primary source of food and wealth (Donald 1997). Together with the interior plateau tribes, who inhabited the upper Columbia and Fraser basins, they represent what is known as the "salmon culture."

Common to the salmon culture was the institution known as the potlatch, an Indian term meaning "to give with the expectation of a return gift" (Barnett 1938). Although there were many variations of the potlatch depending on the occasion, a representative potlatch consisted of a winter ceremony arranged by a tribal chief acting as host of another tribe. The chief gave guests a lavish feast during which they bore witness as he asserted various privileges and justified his claims to productive resources such as fine salmon streams. At the conclusion of the ceremony, the chief distributed gifts to his guests, with the value of the gifts increasing according to the recipient's social prestige. Having accepted these gifts without objection, guests were virtually estopped from disputing the chief's claims at a later time.

Although some authorities question whether potlatch gifts created an obligation to reciprocate (Donald 1997), reciprocity was the norm. Any failure to reciprocate or shortfall in the amount of the return gift raised the social prestige of the more generous party and his tribe. In some regions along the coast, potlatching was highly formalized, and competition for social prestige was intense. Each tribe held a designated social rank that could shift over time depending on its potlatch success (Codere 1950). The potlatch system appears to have involved both direct and indirect reciprocity. Participants could expect to have their generosity returned directly by their former guests. At the same time, the public display of generosity raised their reputation throughout the wider system. Reputation, mediated through gossip, no doubt enhanced the evolutionary stability of cooperation between tribes (Nowak and Sigmund 2005).

In contrast to the egalitarian structure and equalaccess norms associated with hunter-gatherer societies, NWC tribal structure was closer to a corporate form (Trosper 2003). Tribal chiefs held exclusive title to salmon streams and other resources. Trespassers were met with swift and violent retaliation. Chiefs managed their resources as stewards for the tribe, and members contributed their labor to the salmon harvest and other activities under the chief's direction in expectation of receiving a share of the output. The chief retained any residual harvest.

Along with these institutions, the tribes exhibited a remarkably unabashed reverence for the accumulation of wealth and the nearly complete absence of any kind of political or administrative hierarchy resembling the state.

\section{THEORY AND EVIDENCE}

\section{The Natural Abundance Hypothesis}

Imbedded in the traditional view that Pacific salmon were naturally abundant is the hypothesis that the tribes were ignorant of salmon population dynamics. Reflecting the widely held belief of fisheries biologists at the time, in Drucker's words, "it is doubtful whether the Indians understood the life cycle of these fish, ... or connected the spawning with the tiny new-hatched par, or these with the adult salmon" (Drucker 1965). According to the natural abundance hypothesis (NAH), salmon abundance was beyond their ability to influence. Potlatching served simply as a forum to allow tribal chiefs to compete for social prestige and had no functional connection to resource productivity.

Several anthropologists have since proposed that normally abundant salmon stocks were occasionally subject to local failure owing to exogenous environmental shocks. They argue that potlatching functioned as a form of insurance against local starvation on such occasions (Suttles 1962, Piddocke 1965). Although plausible as far as it goes, this proposition accepts the tribes' ignorance of salmon-population dynamics and inability to influence salmon abundance. Moreover, it treats the structure of tribal property rights as given rather than endogenously determined.

For the NWC tribes, ETRs and a strong attachment to place were by no means inevitable. With salmon abundance subject to local variation and beyond the tribes' control, the obvious response would have been to lead a nomadic hunter-gatherer lifestyle rather than a sedentary one. Having low-cost marine transportation in the form of large seaworthy dugout canoes capable of journeying some $1600 \mathrm{~km}(1000$ mi) and more with up to 40 passengers (Fig. 2), they could easily have moved along the coast from one river to the next based on local conditions to harvest 
salmon entering terminal fisheries, as so-called "roving bandits" in an open-access commons (Berkes et al. 2006). With a nomadic lifestyle, they would have had little need for insurance against local resource variation.

Under open access, no one fisher has much incentive to consider the full effect of his or her harvesting decisions on the long-term biological stock because he or she bears the entire cost of forgoing a catch, but captures only a small share of the future benefits from increased returns. Open access severs information feedback about the environmental effect of harvesting decisions and destroys any incentive to invest in local knowledge to enhance long-term productivity or ensure resilience.

The mere observation of ETRs implies some measure of local knowledge accumulation to enhance productivity. As Nobel prize-winning economic historian Douglass North and coauthor Robert Thomas have observed, when open-access rights exist over resources,

...there is little incentive for the acquisition of superior technology and learning. In contrast, exclusive property rights... provide a direct incentive to improve efficiency and productivity, or, in more fundamental terms, to acquire more knowledge and new techniques. It is this change in incentive that explains the rapid progress made by mankind in the last 10 000 years (North and Thomas 1977).

\section{The Salmon Husbandry Hypothesis}

In contrast to the NAH, the alternative hypothesis proposed here, the salmon husbandry hypothesis (SHH), holds that the tribes had substantial knowledge of salmon population dynamics, that they actively accumulated and perpetuated this knowledge, and that they used it to engage in purposeful husbandry of their salmon stocks.

Exclusive property rights are costly to define and enforce. One especially troublesome cost associated with ETRs must have been stream-specific risk owing to local environmental shocks or management errors in the system. Even within fairly close geographic proximity, rivers along the NWC can be differentially affected by flooding, drought, and variations in salinity or temperature that can markedly affect salmon abundance for years to come. A tribe's decision to attach itself to a specific place meant it would have to suffer any resource failure in that locality.

According to the standard risk-return trade-off in economics (Brealey and Myers 1996), there must have been some offsetting benefit in the form of higher expected returns. The opportunity to make husbandry investments to increase the long-term productivity of salmon stocks free from intrusion by rival tribes is the likely benefit. A rudimentary example of such an investment would be a tribal leader's decision to harvest a relatively small proportion of an unexpectedly poor salmon run to allow a larger proportion of the run to spawn and build future generations. So-called "compensatory" fishing would have ensured resilience. In contrast, for a tribe of stable population, the natural tendency for a chief ignorant of salmon population dynamics would have been to harvest a fixed number of salmon from all runs, good or poor, allowing too few to escape and spawn in poor years. This is socalled "depensatory" fishing. One recent study finds that harvesting fish magnifies fluctuations in abundance by truncating the age distribution of the population. This appears to be the outcome of depensatory fishing in an open-access commons, rather than the inevitable outcome of harvesting alone, that under certain conditions can be done in a compensatory way that properly manages effects on the age distribution of the population (Anderson et al. 2008).

\section{Resolving Conflict}

According to the $\mathrm{SHH}$, potlatching was a substitute for violence in enforcing ETRs. Even under stable environmental conditions, there would always have been a tendency for one tribe to encroach on others' territories, the standard tragedy of the commons outcome. However, local environmental shocks would have dramatically increased the tendency for unfortunate tribes to encroach on their more fortunate neighbors. If tribe $\mathrm{A}$ is in the good state of nature with a strong salmon run when tribe B's run is poor, tribe B's labor productivity peacefully fishing its home territory may become dangerously low, whereas tribe A will face ample productive uses for its scarce labor. The resulting differential in relative productivities gives tribe $\mathrm{B}$ a comparative advantage in violence, even though in some senses it is the absolutely weaker tribe (Johnsen 1986, 
Fig. 2. Indian Dugout Canoes. Source: Library of Congress, Prints \& Photographs Division, Edward S. Curtis Collection [reproduction number LC-USZ62-136310].

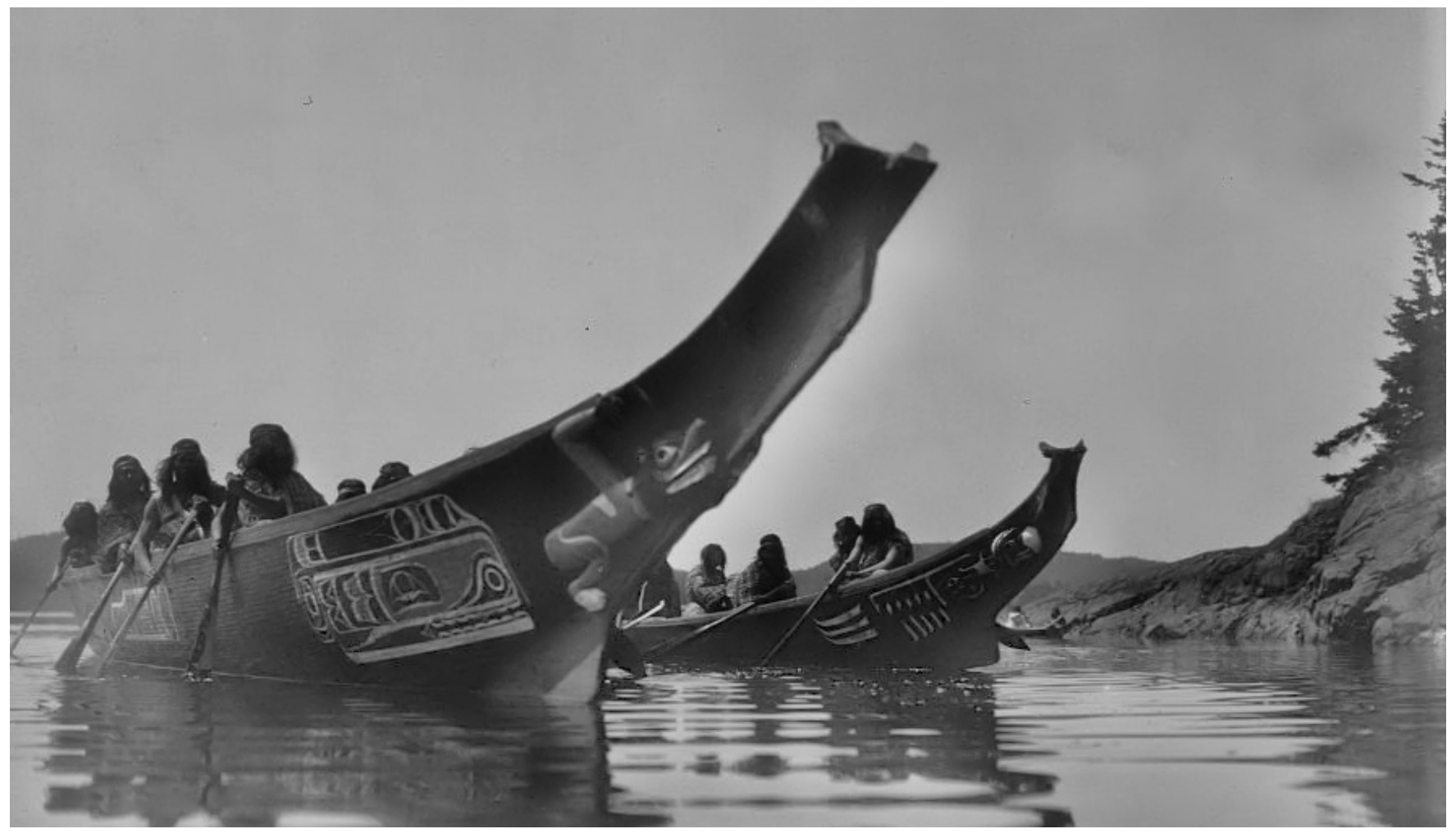

Anderson and McChesney 1994). If tribe B is economically rational, its tendency will be to violently encroach on tribe A's territory.

Owing to the efficiency of long-term husbandry investments, tribe A should be willing and able to compensate tribe B to leave it in peace. What is more, by the definition of risk, the situation is reciprocal. Tribe A knows it is likely at some point to find itself in the poor state and in need of sharing in tribe B's bounty. Costly conflict, or punishment, is avoided (Ohtsuki et al. 2009), and all tribes are better off compared with their state in an openaccess situation.

The war records of the NWC tribes bear repeated accounts of one tribe hearing of another's prosperity and sending its warriors to capture a share of the bounty (Ferguson 1979). In many cases, the encroacher was met with violent retaliation, but as time advanced, target tribes increasingly provided encroachers with tribute to leave in peace. These payoffs gradually evolved into the multilateral network of reciprocal wealth transfers known as potlatching.

Competition between chiefs for social prestige prevented them from underinvesting in building their salmon stocks. Chiefs that were successful resource managers would have been able to consume more, to distribute more within their tribe, and to give away more to rival tribes as potlatch gifts, thereby raising their own, and their tribe's, social prestige. In the event of a poor state, more prestigious tribal leaders could have counted on larger transfers from other tribes. Those tribes who defected by underinvesting would receive smaller transfers or, as a last resort, be excluded from the system entirely (Karthik and Boyd 2004). 


\section{Technology and Information Feedback}

An important attribute of exclusive property rights is that they provide the owner of an asset the option to take advantage of newly discovered opportunities to enhance the asset's value. Knowledge of such growth opportunities requires accurate information feedback. Although the tribes' salmon-harvesting technology included dip nets, spears or harpoons, drift nets, etc., the fish weir was the most sophisticated (Stewart 1977). Construction of a weir involved a substantial capital investment. In many cases, weirs were built to span an entire stream (see Fig. 3). The only way for salmon to pass was to enter a holding trap, giving attendants complete discretion over how many and which salmon were allowed to continue on to the spawning beds.

Compared to a mixed-stock marine fishery subject to a race to first possession, a terminal weir-based fishery free of marine harvesting and subject to ETRs provides relatively noiseless information feedback from harvesting decisions. It would have allowed tribal chiefs to engage in trial and error experimentation akin to scientific hypothesis testing to discover the biological complexity of their salmon stocks. The insurance function of potlatching would have reduced the risk of doing so. Over the long course of generations, systematic knowledge accumulation of salmon population dynamics and husbandry is entirely plausible.

Contrary to Drucker's writing, the tribes seem to have recognized the intergenerational connection between the recurring runs of the individual stocks within a river system. As early as 1868 , one naturalist reported that "[i]t is common practice among the few tribes whose hunters go far inland, at certain seasons, to transport the ova of the salmon in boxes filled with damp mosses, from the rivers to the lakes, or to other streams" (Sproat 1868). Incurring the cost to transplant fertilized ova would have made little economic sense unless the tribes believed that salmon returned to their natal streams to spawn. Otherwise, the costs would have fallen on the transplanters and other tribes would have enjoyed most of the benefits from returning salmon.

Reports of the early spring "first salmon rite," common in some form all along the NWC, confirm that tribal chiefs recognized the intergenerational connection between runs. Following a long winter of limited food production, tribal chiefs prohibited fishing for up to 2 weeks after spotting migrating salmon. Only after a chief ritually caught, cooked, and ate the first salmon could fishing commence under his supervision. The purported reason for delaying the catch was to avoid offending the salmon to ensure they would return in future years (Swezey and Heizer 1977). Berkes (2008) concludes that the first salmon rite was likely an evolved rule of thumb that approximated modern biological management, but the evidence is not inconsistent with a more sophisticated understanding of salmon biology.

Contrasting the coastal tribes' governance with the practices of tribes along the Fraser and Columbia River interiors provides compelling support for the $\mathrm{SHH}$ and casts further doubt on the NAH. In their trunk sections, these rivers were too large to be the subject of ETRs to salmon stocks, although some measure of exclusive access existed over designated fishing stations and smaller tributaries. Salmon migrating upstream to the spawning beds through trunk sections had to "run the gauntlet" of downstream fishing by various tribes. Compared with coastal streams, the trunk-stream fisheries in these rivers were closer to open-access, mixed-stock fisheries similar to our current commercial fisheries.

Indiscriminate harvesting by downstream tribes would have increased the noise of information feedback to upstream tribes in a position to make husbandry decisions in the spawning beds. Because ETRs are costly to enforce, the $\mathrm{SHH}$ predicts that where the benefits in the form of information feedback are lower, the strength of ownership will be lower. Reports indicate that on the Fraser and Columbia Rivers, downstream tribes routinely tolerated trespass by upstream tribes harvesting salmon (Cannon 1992), whereas coastal tribes severely punished such intrusions. Moreover, although practiced in the interior, potlatching was far less formal than along the coast. This evidence is consistent with a weaker system of ETRs in the interior owing to weaker information feedback and less active knowledge accumulation.

Why would coastal tribes engage in harvest and transfer rather than allowing encroachment by unfortunate neighboring tribes, as in the interior? After all, an incumbent tribe with a strong salmon run would have to use its relatively busy labor force to harvest the salmon necessary to pay off potential encroachers. The recipient tribe's labor force would be otherwise underemployed, and the incumbent tribe could therefore gain by allowing the recipient to perform the necessary harvest. 
Fig. 3. Indian Fish Weir. Source: Library of Congress, Prints \& Photographs Division, Edward S. Curtis Collection [reproduction number: LC-USZ62-98669].

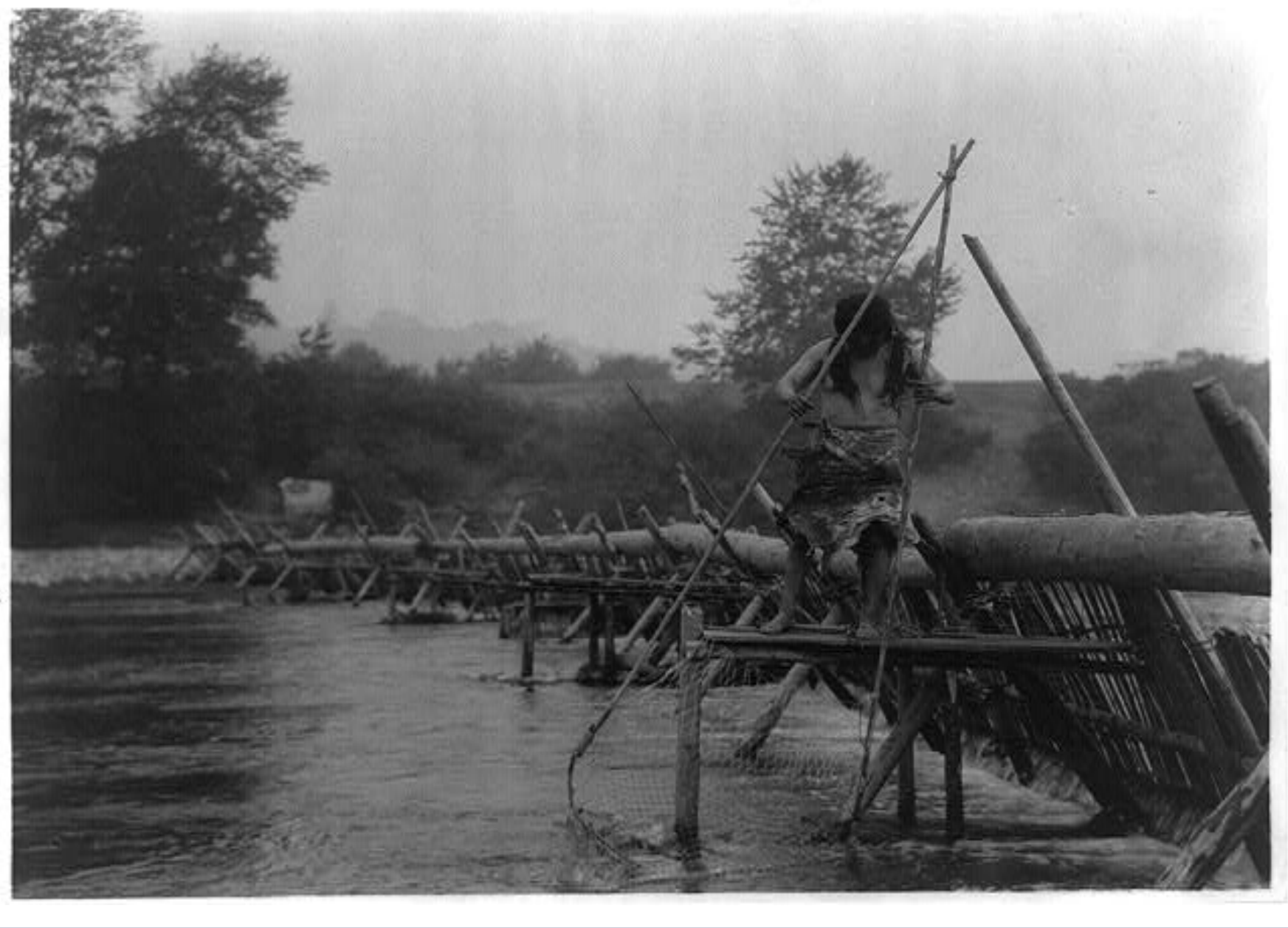

There must have been an offsetting benefit along the coast from resisting encroachment that was markedly lower or absent in the interior. Where information feedback was relatively clear, as along the coast, the informational benefits from excluding others was greater. Coastal tribes no doubt wanted rival tribes to leave their migrating salmon undisturbed for fear of clouding information feedback. In any event, managerial secrecy would have been of paramount importance. That coastal tribes were willing to incur the additional cost of harvest and transfer rather than allowing encroachment strongly supports the SHH.

\section{Knowledge Accumulation and Transfer}

Tribal chiefs were widely known to possess a corpus of knowledge about how best to use their resources to create wealth. Successful chiefs were said to possess "secret knowledge of good behavior," whereas less successful chiefs were "without advice." Although primogeniture was the norm, chiefs routinely bequeathed resources and the associated knowledge to the child identified as having the best mental capacity (Suttles 1958).

So-called "secret societies" appear to have provided for knowledge sharing and transfer to the next generation. It is exactly this knowledge that the 
tribes revered and their chiefs touted at potlatches as the basis for their manifest prosperity. By perpetuating this knowledge, the tribe, like the modern corporation, had the potential for unlimited life supported by a perpetual capital stock of accumulated knowledge, not just for the benefit of existing tribal members but of future generations as well.

\section{CONCLUSION}

The exact extent of the NWC tribes' knowledge of salmon population dynamics is impossible to know based on the available evidence, but it would be difficult to overstate the technological and economic sophistication of the fish weir, which required attendants to make choices about which fish to harvest and which fish to let pass. Over the course of centuries of secure ETRs, variations in harvesting patterns would have been inevitable and, in turn, these would likely have selected in favor of noticeable population mutations. Given the heritability of Pacific salmon and tribal chiefs' virtual ownership of resident salmon stocks, it is entirely plausible that they engaged in purposeful selection to develop populations with preferred biological characteristics. Exclusive tribal rights and potlatch reciprocity played a key role in building a system that was sustainable and resilient (Copes 2000, Trosper 2009).

Salmon have any number of heritable characteristics, including the average size of fish, the calendar timing of their upstream run, the duration of the run, and possibly the extent to which they deteriorate after entering freshwater. To gradually increase the average size of fish in a run, for example, a chief would have had to impose a rule on tribal members to harvest the smaller fish in the run, thereby leaving the larger fish to spawn (Johnsen 2001). Because larger parents give birth to larger offspring, over time the average size of fish would have increased up to some limit. Assuming fixed costs in catching, cleaning, and preserving salmon that were invariant to their size, short-run labor costs could have been reduced by harvesting larger salmon immediately. However, long-run labor costs would have been dramatically reduced by following a small-fish harvesting rule to grow the average size of fish over time.

The first salmon rite provides evidence consistent with purposeful selection. Why would tribal chiefs have allowed early arriving salmon to escape to the spawning beds rather than harvesting immediately, at least to the extent necessary to feed hungry tribal members? One explanation is that they recognized the timing of arrival as heritable. Had they harvested early arrivals and left later arrivals to spawn, subsequent generations would have returned later, compounding the springtime hunger problem. By allowing the earliest arrivals to escape, they would have ensured the early arrival of subsequent generations. Selection for size, timing of arrival, or other characteristics would have been counter to immediate, and possibly pressing, inclinations. Being counterintuitive, rules favoring such selection are unlikely to have evolved incrementally in the absence of some measure of cognition by tribal chiefs confident of secure ownership.

Although the hypothesis that the tribes engaged in purposeful selection is conjectural, it provides the most economically plausible fit with the available evidence. One recent study suggests the tribes purposely engineered "clam gardens" by building extensive rock walls along the low-tide mark that allowed the adjacent beach to backfill with biogenic sand, gravel, and shell debris ideal for promoting clam growth. The same study describes an Indian petroglyph depicting salmon entering a fish weir, accompanied by clusters of tally marks (Williams 2006), apparently indicating a count of salmon escapements. Furthermore, it has long been recognized that the tribes actively engaged in herring-spawn-on-kelp aquaculture (Stewart 1977).

It is essential to put archaeologists, ecologists, economists, historians, fisheries biologists, and other researchers on notice of the SHH so they can assess it within the context of their own accumulating body of scientific knowledge. It is also essential for fisheries regulators, NWC tribes, and others concerned with the future of the Pacific salmon fishery to be mindful of the potential value to be created by moving to a system of privateproperty rights in salmon stocks. The evidence suggests that creation of individual catch shares may be a first successful step along the way (Costello et al. 2008). For Pacific salmon, there can be little doubt in the abstract that terminal, river-based fishing of identified stocks dominates marine fishing of mixed stocks under open access and possibly even individual catch shares. Rather than endless political wrangling over a shrinking pie, a move to terminal fisheries could so dramatically improve productivity that winners would be able to compensate losers from reorganizing the system. 
Responses to this article can be read online at: http://www.ecologyandsociety.org/voll4/iss2/art43/ responses/

\section{Acknowledgments:}

I thank Fikret Berkes, Mimi Lam, Nancy McCarthy, Elinor Ostrom, and Mark Plummer for helpful comments and encouragement. I also thank the Property and Environment Research Center, the Law and Economics Center at George Mason University School of Law, and the Marine Conservation Initiative at the Gordon and Betty Moore Foundation for generous financial assistance.

\section{LITERATURE CITED}

Anderson, C. N. K., C. Hsieh, S. A. Sandin, R. Hewitt, A. Hollowed, J. Beddington, R. M. May, and G. Sugihara. 2008. Why fishing magnifies fluctuations in fish abundance. Nature 452:835839.

Anderson, T. L., and F. S. McChesney. 1994. Raid or trade? An economic model of Indian-white relations. Journal of Law and Economics 37(1):3974.

Barnett, H. G. 1938. The nature of the potlatch. American Anthropologist 40:349-358.

Berkes, F. 2008. Sacred ecology. Routledge, New York, New York, USA.

Berkes, F., T. P. Hughes, R. S. Steneck, J. A. Wilson, D. R. Bellwood, B. Crona, C. Folke, L. H. Gunderson, H. M. Leslie, J. Norberg, M. Nyström, P. Olsson, H. Österblom, M. Scheffer, and B. Worm. 2006. Globalization, roving bandits, and marine resources. Science 311:1557-1558.

Boas, F. 1966. Kwakiutl ethnography. University of Chicago Press, Chicago, Illinois, USA.

Brealey, R. A., and S. C. Myers, S. C. 1996. Principles of corporate finance. Fifth edition. McGraw-Hill, New York, New York, USA.

Coase, R. H. 1960. The problem of social cost. Journal of Law and Economics 3:1-36.
Cannon, A. 1992. Conflict and salmon on the interior plateau of British Columbia. Pages 506-524 in $\mathrm{B}$. Hayden, editor. A complexculture of the British Columbia plateau: traditional Stl'atl'imx resource use. University of British Columbia Press, Vancouver, B.C., Canada.

Codere, H. 1950. Fighting with property. Monographs of the American Ethnological Society 18.

Copes, P. 2000. Aboriginal fishing rights and salmon management in British Columbia: matching historical justice with the public interest. Pages 7591 in E. E. Knudsen, C. Steward, D. MacDonald, J. Williams, and D. Reiser, editors. Sustainable fisheries management: pacific salmon. CRC Press, Boca Raton, Florida, USA.

Costello, C., S. D. Gaines, and J. Lynham. 2008. Can catch shares prevent fisheries collapse? Science 321:1678-1681.

Dietz, T., E. Ostrom, and P. C. Stern. 2003. The struggle to govern the commons. Science 302:19071912.

Donald, L. 1997. Aboriginal slavery on the Northwest Coast of North America. University of Chicago Press, London, UK.

Drucker, P. 1965. Cultures of the north Pacific Coast. Addison-Wesley, London, UK.

Dumbacher, J. M., P. A. Rossignol, H. W. Li, and J. M. Emlen. 2001. Dam breaching and Chinook salmon recovery. Science 291:939.

Ferguson, B. 1979. Warfare and redistributive exchange on the Northwest Coast. Pages 133-147 in E. Tooker, editor. The development of political organizations in native NorthAmerica. Proceedings of the American Ethnological Society 133. Washington, D.C., USA.

Hardin, G. 1968. The tragedy of the commons. Science 162: 1243-1248.

Harris, D. C. 2001. Fish, law, and colonialism in the legal capture of salmon in British Columbia. University of Toronto Press, Toronto, Ontario, Canada.

Harris, D. C. 2008. Landing native fisheries: Indian reserves and fishing rights in British Columbia, 
1845-1925. University of British Columbia Press, Vancouver, B.C., and Toronto, ON, Canada.

Hayden, B. 1981. Research and development in the stone age: technological transitions among huntergatherers. Current Anthropology 22:519-548.

Hendry, A. P., J. K. Wenburg, P. Bentzen, E. C. Volk, and T. P. Quin. 2000. Rapid evolution of reproductive isolation in the wild: evidence from introduced salmon. Science 290:516-518.

Johnsen, D. B. 1986. The formation and protection of property rights among the southern Kwakiutl Indians. Journal of Legal Studies 15:41-67.

Johnsen, D. B. 2001. Customary law, scientific knowledge, and fisheries management among Northwest Coast tribes. New York University Environmental Law Journal 10:1-69.

Kareiva, P., M. Marview, and M. McClure. 2000. Recovery and management options for spring/ summer Chinook salmon in the Columbia River Basin. Science 290:977-979.

Karthik, P., and R. Boyd. 2004. Indirect reciprocity can stabilize cooperation without the second-order free rider problem. Nature 432:499502.

Langdon, S. 1979. Comparative Tlingit and Haida adaptation to the west coast of the Prince of Wales Archiplego. Ethnology 18:101-119.

Mann, C. C., and M. L. Plummer. 2000. Can science rescue salmon? Science 289:716-719.

Marsh, G.P. 1874. The earth as modified by human action. Scribner, Armstrong and Company, New York, New York, USA.

North, D. C., and R. P. Thomas. 1977. The first economic revolution. The Economic History Review 30:229-241.

Nowak, M. A., and K. Sigmund. 2005. Evolution of indirect reciprocity. Nature 437:1291-1298.

Ohtsuki, H., Y. Iwasa, and M. A. Nowak. 2009. Indirect reciprocity provides only a narrow margin of efficiency for costly punishment. Nature 457:7982.
Ostrom, E., J. Burger, C. B. Field, R. B. Norgaard, and D. Policansky. 1999. Revisiting the commons: local lessons, global challenges. Science 284:278-282.

Piddocke, S. 1965. The potlatch system of the southern Kwakiutl. Southwestern Journal of Anthropology 21:244-264.

Sproat, G. 1868. Scenes and studies of savage life. Smith, Elder and Company. London, UK.

Stewart, H. 1977. Indian fishing: early methods on the Northwest Coast. University of Washington Press, Seattle, Washington, USA.

Suttles, W. 1958. Private knowledge, morality, and social classes among the Coast Salish. American Anthropology 60:497-507.

Suttles, W. 1962. Variation in habitat and culture on the Northwest Coast. Pages 522-537 in O. Grunow, editor. Proceedings of the 34th International Congress of Americanists. University of Chicago Press, Chicago, Illinois, USA.

Swezey, S. L., and R.F. Heizer. 1977. Ritual management of salmonid fish resources in California. Journal of California Anthropology 4 (1):5. [online] URL: http://repositories.cdlib.org/uc mercedlibrary/jca/vol4/iss1/art5.

Trosper, R. L. 2003. Resilience in pre-contact Pacific Northwest social ecological systems. Conservation Ecology 7(3): 6. [online] URL: URL: http://www.ecologyandsociety.org/vol7/iss3/art6/.

Trosper R. L. 2009. Resilience, reciprocity and ecological economics: Northwest Coast sustainability. Routledge, New York, New York, USA.

Williams, J. 2006. Clam gardens: aboriginal mariculture on Canada's west coast. New Star Books, Vancouver, B.C., Canada. 